\title{
Caracterização florística e fitofisionômica da Serra do Condado, Minas Gerais, Brasil
}

\author{
Daniel Salgado Pifano ${ }^{1,4}$, Arthur Sérgio Mouco Valente ${ }^{1}$, Hisaias de Souza Almeida ${ }^{1}$ \\ Pablo Hendrigo Alves de Melo ${ }^{1}$, Ricardo Montianeli de Castro ${ }^{2}$ \& Eduardo van den Berg ${ }^{3}$ \\ ${ }^{1}$ Programa de Pós-graduação em Engenharia Florestal, Universidade Federal de Lavras - UFLA, \\ CP 3037, CEP 37200-000 Lavras, MG, Brasil, e-mail: spgdcf@ufla.br \\ ${ }^{2}$ Programa de Pós-graduação em Botânica,Universidade Estadual de Feira de Santana - UEFS, \\ CEP 44031-460 Feira de Santana, BA, Brasil \\ ${ }^{3}$ Departamento de Biologia, Universidade Federal de Lavras - UFLA, \\ CP 3037, CEP 37200-000 Lavras, MG, Brasil,e-mail: evandenb@ufla.br \\ ${ }^{4}$ Autor para correspondência: Daniel Salgado Pifano,e-mail:danielfloristico@yahoo.com.br
}

PIFANO, D.S., VALENTE, A.S.M., ALMEIDA, H.S., MELO, P.H.A., CASTRO, R.M. \& van der BERG, E. Floristic and phytophysiognomies characterization of the Serra do Condado, Minas Gerais, Brazil. Biota Neotrop., 10(1): http://www.biotaneotropica.org.br/v10n1/en/abstract?article+bn01010012010.

\begin{abstract}
Little is known about the flora of the Espinhaço Sul range. However, the environmental conservation of such complex has been threatened, mainly due to the potential mineral richness lying there. The aim of this study was to the floristic and physiognomy characterization of Serra do Condado, located in the Serro County, MG. Thus, fortnight field campaigns were carried out during the period of May/2006 to May/2007, in order to collect floristic material and to characterize the area. Furthermore, the value in area of each physiognomic in the constitution of the landscape was made through the software ArGis 9.0 and the floristic similarity among the observed physiognomic aspects, were tested by the Sørensen similarity index. Atlantic Semideciduos Montane Forests, Riparian Forests, Swamps and Woody Shrub Vegetation over "Canga" were found in the area. Semidecidual Forest corresponds to $80 \%$ of the local vegetation, presenting 426 species (391 exclusives) distributed in 83 families. The families that had the largest number of species were Fabaceae (40), Asteraceae (30) and Myrtaceae (30). Following came, Woody Shrub Vegetation over "Canga", covers $13 \%$ of the studied area, and in it were found 94 species (74 exclusives), distributed among 29 families. Asteraceae (9), Orchidaceae (7) e Bromeliaceae (5) were distinguished by their species abundance in this physiognomy. Riparian Forests are not so representative, constituting only $5 \%$ of the forested area. In this physiognomy, 74 species ( 54 exclusives) belonging to 28 families were found, of these, Fabaceae (7), Piperaceae (4) and Annonaceae (3) were the most representative ones. Due to anthropogenic disturbances, Swamps cover only $2 \%$ of the area. As it showed characteristics such as constant hydric saturation it had the highest proportion of exclusive found species, 18 out of 19, being Cyperaceae and Melastomataceae (5) the richest families. The flora found at Serra do Condado was differentiated in relation to their habitats (physiognomies), because the values obtained by the Sørensen index were less than $10 \%$ for all other comparisons. This shows how fundamental floristic studies are for knowing the vegetation of areas being both geographically extensive and biologically diverse. The great variety of environment presented and the flora richness associated to this formation aggregate conservation and maintenance value to the Espinhaço Sul range flora, Minas Gerais.

Keywords: floristic similarity, canga, Espinhaço range, diversity, Atlantic Domain.
\end{abstract}

PIFANO, D.S., VALENTE, A.S.M., ALMEIDA, H.S., MELO, P.H.A., CASTRO, R.M. \& van der BERG, E. Caracterização florística e fitofisionômica da Serra do Condado, Minas Gerais, Brasil. Biota Neotrop., 10(1): http://www.biotaneotropica.org.br/v10n1/pt/abstract?article+bn01010012010.

Resumo: O complexo serrano do Espinhaço Sul é ainda floristicamente desconhecido e a conservação destas serras está ameaçada em função de sua exclusiva riqueza mineral. A Serra do Condado, localizada no município de Serro, MG (18 37' 30" S e 43 22' 30" W) é um bom exemplo de como as atividades de mineração estão distantes da conservação destes ecossitemas e por tal razão o presente estudo teve como objetivo a caracterização florística e fitofisionômica desta serra. As campanhas de campo foram quinzenais e ocorreram entre os meses de maio/2006 a maio/2007. Foram coletados apenas os materiais botânicos em estágio fenológico reprodutivo. Os mesmos foram incorporados aos acervos dos herbários CESJ, RB e ESAL. O valor em área de cada fisionomia na constituição da paisagem foi feito através do software ArGis 9.0 e a similaridade florística entre as fisionomias foi realizada mediante cálculo do índice de Sørensen. Na área estudada foram encontradas Florestas Estacionais Semideciduais Montanas, Matas Ciliares, Brejos e Vegetação Arbustivo-Lenhosa sobre Canga. A floresta semidecídua montana corresponde a $80 \%$ da vegetação local, apresentando 426 espécies (391 exclusivas) distribuídas em 83 famílias. As famílias com maior número de espécies foram Fabaceae (40), Asteraceae (30) e Myrtaceae (30). A floresta ciliar é pouco representativa, cobrindo $5 \%$ da área florestada. Nessa formação foram encontradas 74 espécies 
Pifano, D.S. et al.

(54 exclusivas) pertencentes a 28 famílias. As famílias mais representativas foram Fabaceae (sete), Piperaceae (quatro) e Annonaceae (três). Os brejos, devido a perturbações antrópicas, cobrem apenas 2\% da área. Por fatores como a saturação hídrica constante essa fitofisionomia apresentou o maior número de espécies exclusivas, 18 das 19 encontradas, sendo Cyperaceae e Melastomataceae (cinco) as famílias mais ricas. A Vegetação arbustivo-lenhosa sobre canga cobre 13\% da área. Nela foram encontradas 94 espécies (74 exclusivas), distribuídas em 29 famílias. Asteraceae (nove), Orchidaceae (sete) e Bromeliaceae (cinco) destacaram-se pela riqueza de espécies nessa fisionomia. A flora da Serra do Condado foi diferenciada entre seus hábitats (fitofisionomias), pois os valores obtidos para o índice de Sørensen foram inferiores a $10 \%$ em todas as comparações. Isso demonstra o quanto estudo florísticos são fundamentais para o conhecimento da vegetação de áreas extensas geograficamente e diversas biologicamente. A variedade de ambientes apresentados e a riqueza da flora associada às suas formações agregam valor de conservação e manutenção da flora dos complexos serranos do Espinhaço Sul de Minas Gerais.

Palavras-chave: similaridade florística, canga, cadeia do Espinhaço, diversidade, Domínio Atlântico.

\section{Introdução}

O estado de Minas Gerais abrange as principais fisionomias florestais do Domínio Atlântico, o qual corresponde a aproximadamente $35 \%$ do território estadual. No entanto, é a fisionomia da Floresta Estacional Semidecidual que predomina, constituindo mais de $85 \%$ da área florestal original deste Domínio em Minas Gerais (Scolforo \& Carvalho 2006). A Cadeia do Espinhaço é parte fronteiriça deste mosaico e é considerada área prioritária para conservação da Flora de Minas Gerais, devido à concentração do maior número de endemismos do país e também do maior número de táxons fanerogâmicos considerados raros, tudo isso considerando toda a flora nacional (Drummond et al. 2005, Giulietti et al. 2008).

Mesmo sendo prioridade em termos de conservação, a cobertura florestal primitiva desta região de Minas Gerais foi reduzida a remanescentes esparsos, uma vez que o histórico de perturbação dessas áreas sempre esteve atrelado à forte atividade minerária (Brandão \& Gavilanes 1990). De fato, a mineração vem modificando abruptamente os Complexos Rupestres de Altitude no Espinhaço, principalmente em sua vertente mais ao sul (Dean 1996, Werneck et al. 2000).

Estudos florísticos são importantes em países como o Brasil, pois revelam em seus resultados informações capazes de diminuir a discrepância de recursos públicos destinados ao crescimento econômico em detrimento do que é investido para frear a perda de biodiversidade consequente ao mesmo e, nesse intuito, muitos têm sido concentrados na Cadeia do Espinhaço, especialmente em solos quartzíticos (Andrade et al. 1986, Giulietti et al. 1987, Meguro et al. 1994, Stannard 1995, Conceição \& Giulietti 2002). Já a vegetação sobre canga, conta com um número menor de levantamentos e os mesmos são recentes, com destaque apenas para os trabalhos realizados na região do Quadrilátero Ferrífero (Mourão \& Stehmann 2007, Viana \& Lombardi 2007, Vincent \& Meguro 2008). Certamente, o maior esforço de trabalho ainda concentra-se nas florestas da bacia do rio Doce (Lombardi \& Gonçalves 2000, Werneck et al. 2000, Melo \& Salino 2002, Lopes et al. 2002) e Jequitinhonha (Néri et al. 2007).

Esses trabalhos e outros desenvolvidos na região sudeste têm demonstrado a existência de diferenças significativas na composição florística e na estrutura de remanescentes localizados em áreas relativamente próximas (Oliveira-Filho et al. 2005). No fim do século XX surgiu a preocupação em usar métodos numéricos para comparar a ocorrência de espécies, testar as associações e, então, definí-las, com base nas relações florísticas estabelecidas quantitativamente por índices de similaridade (Silva \& Shepherd 1986, Oliveira-Filho1993, Oliveira-Filho \& Ratter 1995, Araújo 1998, Scudeller 2002). Porém, estudos como esses ainda são pouco numerosos ou tratam apenas de uma formação vegetal (Oliveira-Filho et al. 1994a, 1994b, Salis et al. 1995, Torres et al. 1997, Oliveira-Filho \& Fontes 2000,
Scudeller et al. 2001). Nesse sentido, as conexões florísticas das fitofisionomias que compõem o Domínio Atlântico também são pouco conhecidas, haja vista que os trabalhos realizados bem como os métodos de análise encerram-se apenas no componente arbóreo dessas florestas (Gentry 1990, Oliveira-Filho \& Fontes 2000, Oliveira-Filho et al. 2005, Pereira et al. 2007, Murray-Smith et al. 2008). Estudos florísticos que consideram todas as formas de vida e com informações fitogeográficas mensuráveis, ou seja, com registros em herbários dos materiais testemunho, são fundamentais na compreensão das relações existentes entre as fisionomias que compõem o Domínio Atlântico e ainda são escassos pelo alto tempo demandado associado à inerente freqüência em campo exigida por tais levantamentos.

A escassez de informações, aliada à crescente intervenção antrópica sobre os ambientes naturais motivaram o desenvolvimento do presente estudo, que teve como objetivos caracterizar a composição da flora vascular das diferentes fitofisionomias presentes na Serra do Condado no município de Serro, Minas Gerais investigando a composição e similaridade entre as fisionomias de vegetação, além de fornecer a descrição e a caracterização das mesmas.

\section{Material e Métodos}

\section{1. Área de estudo}

O município do Serro (Figura 1) está situado na microrregião de Conceição do Mato Dentro onde destacam-se as intrusões de minério de ferro que afloram especialmente no alto das serras. A região está inserida no domínio geomorfológico da Serra do Espinhaço, com formas fluviais de dissecação (CETEC, 1983). A área de estudo (18 $31^{\prime} 19^{\prime \prime} \mathrm{S}-43^{\circ} 22^{\prime} 38^{\prime \prime} \mathrm{O}$ e $18^{\circ} 34^{\prime} 47^{\prime \prime} \mathrm{S}-43^{\circ} 23^{\prime} 36^{\prime \prime} \mathrm{O}$ ) está localizada na borda oriental deste domínio, numa elevação topográfica localmente denominada Serra do Condado, com extensão territorial aproximada de 1000 ha, num relevo regional extremamente movimentado, cujas altitudes variam de 805 a $1.135 \mathrm{~m}$.

O clima regional (classificação de Köppen) é do tipo Cwa: mesotérmico úmido subtropical, com verão quente e chuvas concentradas, e inverno frio e seco com mais de 120 dias de estiagem por ano. De acordo com os dados disponíveis no Sistema de Meteorologia e Recursos Hídricos de Minas Gerais (SIMGE), na área de estudo a precipitação anual média anual é de $1.515 \mathrm{~mm}$ e a temperatura média anual é de $18,3{ }^{\circ} \mathrm{C}$.

A cobertura vegetal da área de estudo (Figura 1) é marcada por gradientes vegetacionais que incluem diversas fisionomias do Domínio Atlântico, Floresta Estacional Semidecidual Montana, Floresta Estacional Semidecidual Aluvial (tratadas aqui como Mata Ciliar), Vegetação Arbustivo-Lenhosa sobre Canga, Campo Rupestre 

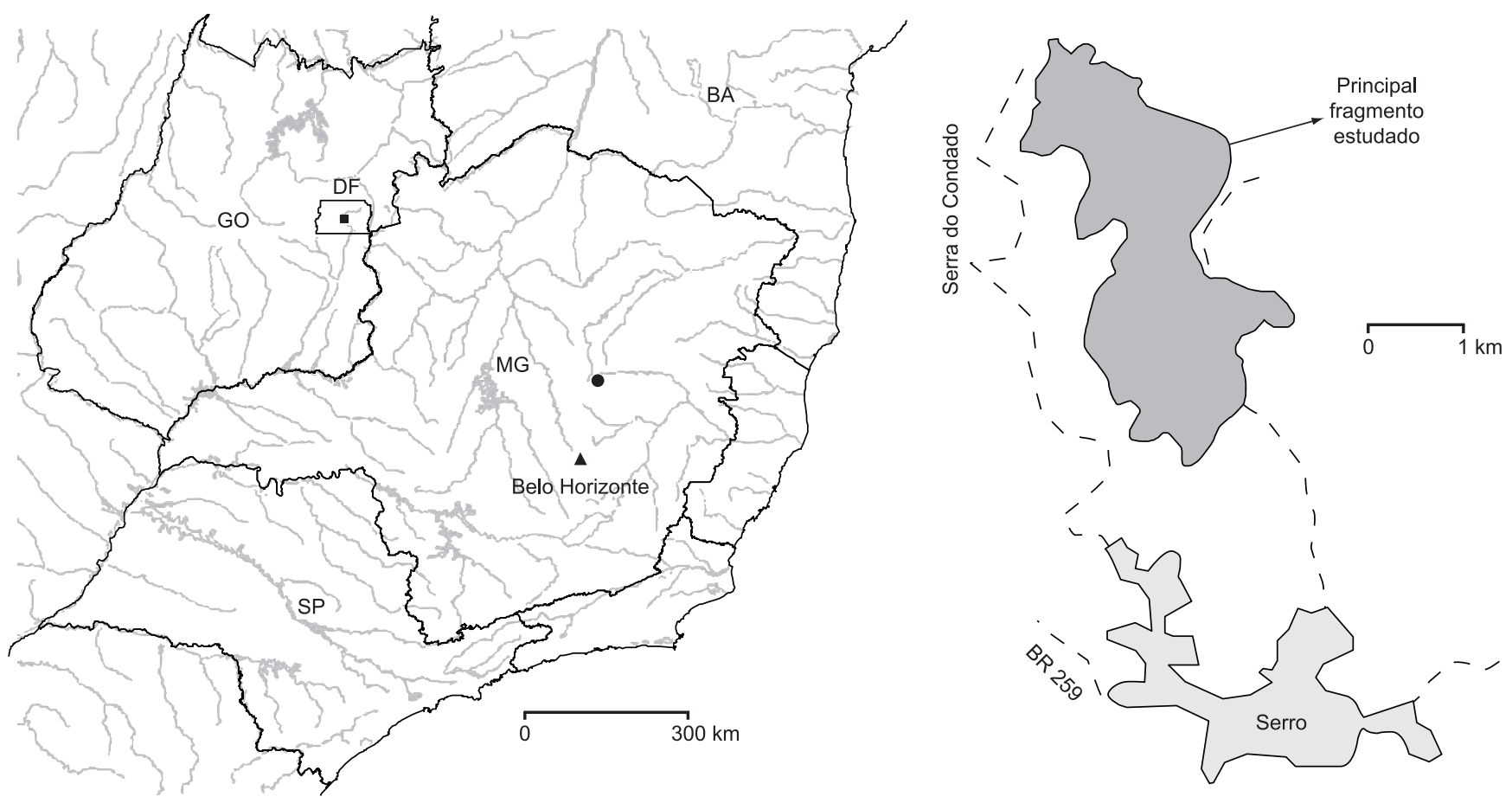

Figura 1. Localização da Serra do Condado, município de Serro, MG

Figure 1. Geographic situation of the Serra do Condado, Serro County, MG

e Brejos, segundo a classificação de Veloso et al. (1991), exceto para a Vegetação Arbustivo-Lenhosa sobre Canga que ainda não possui um concenso terminológico definido. Trata-se de uma Área de Proteção Ambiental - a APA Água das Vertentes - com trechos antropizados (principalmente destinados à pecuária bovina) e extensas áreas de floresta em diferentes estádios sucessionais.

\section{Coleta e análise dos dados}

A caracterização das fitofisionomias presentes na área de estudo seguiu critérios elaborados por Veloso et al. (1991) e foi realizada baseando-se em observações de campo e na composição de espécies. A quantificação em área de cada fitofisionomia foi realizada com o auxílio do software ArcGis 9.3, de mapas e imagens disponibilizadas pelo setor de geoprocessamento do Departamento de Engenharia Florestal da Universidade Federal de Lavras.

O levantamento florístico foi realizado através de coletas quinzenais entre os meses de maio de 2006 e maio de 2007, percorrendo-se todas as fitofisionomias da área de estudo, numa extensão amostrada de aproximadamente 500 ha na Serra do Condado, ou seja, praticamente a metade de toda a extensão territorial da mesma. É importante mencionar que a outra metade não foi contemplada por questões de acesso, fundiárias e de propriedade, já que em muitas fazendas não se obteve a autorização do proprietário para a execução do estudo. Foram coletados e herborizados, segundo técnicas padronizadas por Fidalgo \& Bononi (1984), todos os espécimes de plantas vasculares encontradas em estado fenológico reprodutivo. As exsicatas foram incorporadas aos acervos dos herbários CESJ da Universidade Federal de Juiz de Fora, RB do Jardim Botânico do Rio de Janeiro e ESAL da Universidade Federal de Lavras.

A determinação dos táxons fundamentou-se em literatura especializada (principalmente para as Pteridophyta), além de consultas a especialista e a herbários nacionais. Os táxons foram classificados em famílias segundo o sistema da APGII (2003) e através da obra de Souza \& Lorenzi (2008). Para o grupo Pteridophyta, as famílias de monilófitas estão de acordo com Smith et al. (2006), as de Lycophyta seguem Tryon, R. M. \& Tryon, A. F. (1982). É importante mencionar que, na separação dos hábitos, as arvoretas foram incluídas entre as arbóreas, sendo as plantas eretas e lenhosas distintas apenas como arbustos ou árvores. Para tal, seguiu-se a classificação das formas de vida de Raunkiaer (1934) adaptada aos conceitos de organografia atuais. A estimativa da similaridade entre as fitofisionomias seguiu as fórmulas descritas em Kent \& Coker (1992), para o índice de Sørensen.

\section{Resultados}

O levantamento florístico da vegetação da Serra do Condado, em todos seus hábitats, registrou 575 espécies, distribuídas em 336 gêneros e 107 famílias de plantas vasculares (Tabela 1). As famílias com maior número de espécies foram: Fabaceae (51), Asteraceae (45), Myrtaceae (39) Melastomataceae (24), Rubiaceae (22) e Euphorbiaceae (18). Algumas famílias com elevada riqueza em áreas inseridas em Complexos Rupestres de Altitude, como Poaceae e Orchidaceae, foram subamostradas neste estudo que concentrou os maiores esforços de coleta nos hábitats florestais.

A Floresta Estacional Semidecidual Montana constituiu 80\% da vegetação local em termos de área e está localizada entre as cotas altitudinais de 600 a 900 m, já que acima deste limite se encotram zonas ecotonais de Floresta Montana e Vegetação Arbustivo-Lenhosa sobre Canga. Os fragmentos de floresta montana apresentam-se sob a forma de manchas esparsas em diferentes estádios de sucessão e estão localizados em encostas íngremes e nos topos de morro. Em grande parte os fragmentos evidenciavam efeito de borda acentuado em função dos acessos abertos para a corrida minerária que se instalou no local. Nesses locais, destaca-se a presença de pequenas árvores exigentes de luz como Mabea fistulifera Mart., Mabea pohliana (Benth.) Müll.Arg., Miconia latecrenata (DC.) Naudin e Miconia sellowiana Naudin. A heterogeneidade microclimática definiu a ocorrência e distribuição, nos hábitats úmidos, das poucas macroepífitas encontradas como a Orchidaceae Polystachya sp. e a Bromeliaceae 
Pifano, D.S. et al.

Tabela 1. Espécies inventariadas na Serra do Condado, Serro, $M G$, Brasil segundo seu hábito $(A R B=$ Arbusto, $A R V=$ Árvore, $E R V=$ Erva, $E R V . A R=$ Erva arborescente, TREP $=$ Trepadeira, H.PAR $=$ Hemiparasitas $;$ HOPA $=$ Holoparasitas; EPI $=$ Epífitas $)$, hábitat de ocorrência $(1=$ Floresta Estacional Semidecidual Montana, 2 = Mata Ciliar, 3 = Brejo e 4 = Vegetação arbustivo-lenhosa sobre canga) e número de coletor $($ Cas $=$ R.M.Castro, Pif $=$ D.S.Pifano \& Val = A.S.M.Valente)

Table 1. Species sampleds at Range mountain of the Serra do Condado, Serro County, MG, Brazil by habitat $(A R B=S h r u b, A R V=$ Tree, ERV $=$ Herbaceus, ERV.AR = Woody Herbaceus, TREP = Vines, H.PAR = Hemiparasits; HOPA = Holoparasits; EPI = Epiphytes $)$, occurrence habitat $(1=$ Montane Semidecidual Atlantic Forest, $2=$ Riverine forest, $3=$ Heath and $4=$ Woody-Shrub vegetation on Canga) and voucher specimens $($ Cas $=$ R.M.Castro, Pif $=$ D.S.Pifano \& Val = A.S.M.Valente).

\begin{tabular}{|c|c|c|c|}
\hline Família/Espécie & Hábito & Hábitats & Material testemunho \\
\hline \multicolumn{4}{|l|}{ ACANTHACEAE } \\
\hline Geissomeria schottiana Nees & ARB & 2 & Cas 1296 \\
\hline Herpetacanthus rubiginosus Nees & ARB & 2 & Cas 1275 \\
\hline Justicia sp. & ERV & 1,2 & Pif 589 \\
\hline Mendoncia coccinea Vell. & TREP & 1 & Cas 1365 \\
\hline Ruellia elegans Poir. & ERV & 1 & Pif 630 \\
\hline Acanthaceae indet. & $\mathrm{ARB}$ & 2 & Pif 709 \\
\hline \multicolumn{4}{|l|}{ ALISMATACEAE } \\
\hline Echinodorus macrophyllus (Kunth) Micheli & ERV & 3 & Cas 1372 \\
\hline \multicolumn{4}{|l|}{ AMARANTHACEAE } \\
\hline Alternanthera brasiliana (L.) Kuntze & ERV & 1 & Pif 632 \\
\hline \multicolumn{4}{|l|}{ ANACARDIACEAE } \\
\hline Astronium fraxinifolium Schott ex Spreng. & ARV & 1 & Val 403 \\
\hline Schinus terebinthifolius Raddi & ARV & 2 & Val 448 \\
\hline Tapirira guianensis Aubl. & ARV & 1 & Cas 1269 \\
\hline Tapirira obtusa (Benth.) J.D.Mitch. & ARV & 1 & Pif 730 \\
\hline \multicolumn{4}{|l|}{ ANNONACEAE } \\
\hline Annona cacans Warm. & ARV & 1 & Pif 745 \\
\hline Duguetia lanceolata A.St.-Hil. & ARV & 1 & Cas 1207 \\
\hline Guatteria australis A.St.-Hil. & ARV & 1 & Val 471 \\
\hline Guatteria villosissima A.St.-Hil. & ARV & 1 & Val 455 \\
\hline Oxandra sp. & ARV & 2 & Pif 733 \\
\hline Rollinia laurifolia Schltdl. & ARV & 1 & Cas 1235 \\
\hline Rollinia leptopetala R.E.Fr. & ARV & 2 & Pif 647 \\
\hline Rollinia mucosa (Jacq.) Baill. & ARV & 1 & Val 405 \\
\hline Rollinia sylvatica (A.St.-Hil.) Mart. & ARV & 1 & Pif 613 \\
\hline Xylopia aromatica (Lam.) Mart. & ARV & 1 & Cas 669 \\
\hline Xylopia brasiliensis Spreng. & ARV & 1 & Pif 632 \\
\hline Xylopia emarginata Mart. & ARV & 2 & Pif 624 \\
\hline Xylopia sericea A.St.-Hil. & ARV & 1 & Cas 1311 \\
\hline \multicolumn{4}{|l|}{ APOCYNACEAE } \\
\hline Asclepias curassavica $\mathrm{L}$. & $\mathrm{ARB}$ & 1 & Pif 452 \\
\hline Aspidosperma australe Müll.Arg. & ARV & 1 & Pif 436 \\
\hline Aspidosperma cylindrocarpon Müll.Arg. & ARV & 4 & Cas 779 \\
\hline Aspidosperma parvifolium A.DC. & ARV & 1 & Cas 1423 \\
\hline Aspidosperma pyrifolium Mart. & ARV & 1 & Pif 396 \\
\hline Blepharodon nitidum (Vell.) J.F.Macbr. & TREP & 4 & Val 460 \\
\hline Ditassa eximia Decne. & TREP & 4 & Cas 1126 \\
\hline Himatanthus lancifolius (Müll.Arg.) Woodson & ARV & 1 & Pif 651 \\
\hline Mandevilla scabra (Roem. \& Schult.) K. Schum. & TREP & 4 & Pif 395 \\
\hline Prestonia tomentosa $\mathrm{R} . \mathrm{Br}$. & TREP & 1 & Pif 656 \\
\hline Stipecoma peltigera (Staldem.) Mull.Arg. & TREP & 4 & Pif 753 \\
\hline \multicolumn{4}{|l|}{ AQUIFOLIACEAE } \\
\hline Ilex affinis Gardn. & ARV & 1 & Pif 724 \\
\hline Ilex brevicuspis Reissek & ARV & 1 & Morfoesp \\
\hline
\end{tabular}


Tabela 1. Continuação...

\begin{tabular}{|c|c|c|c|}
\hline Família/Espécie & Hábito & Hábitats & Material testemunho \\
\hline Ilex cerasifolia Reissek & ARV & 1 & Morfoesp \\
\hline Ilex sapotifolia Reissek & ARV & 1 & Pif 736 \\
\hline Ilex theezans Mart. ex Reissek & ARV & 1 & Pif 449 \\
\hline \multicolumn{4}{|l|}{ ARACEAE } \\
\hline Anthurium solitarium (Vell.) Schott & EPI & 2 & Cas 539 \\
\hline Anthurium sp. & EPI & 2 & Val 452 \\
\hline Anthurium sp. 2 & EPI & 1 & Pif 751 \\
\hline Philodendron sp. & EPI & 2 & Pif 442 \\
\hline \multicolumn{4}{|l|}{ ARALIACEAE } \\
\hline Schefflera calva (Cham.) Frodin \& Fiaschi & ARV & 1 & Val 453 \\
\hline Schefflera morototoni (Aubl.) Maguire, Steyerm. \& Frodin & ARV & 1 & Cas 1129 \\
\hline \multicolumn{4}{|l|}{ ARECACEAE } \\
\hline Acrocomia aculeata (Jacq.) Lodd. ex Mart. & ARV & 1 & Pif 735 \\
\hline Geonoma schottiana Mart. & ERV.AR & 2 & Pif 385 \\
\hline \multicolumn{4}{|l|}{ ARISTOLOCHIACEAE } \\
\hline Aristolochia grandiflora $\mathrm{Sw}$. & TREP & 1 & Val 331 \\
\hline Aristolochia sp. & TREP & 1 & Val 297 \\
\hline \multicolumn{4}{|l|}{ ASTERACEAE } \\
\hline Acanthospermum australe (Loefl.) Kuntze & ERV & 1 & Cas 1379 \\
\hline Achyrocline satureioides (Lam.) DC. & ERV & 1 & Pif 661 \\
\hline Acritopappus confertus (Gardner) R.M. King \& H. Rob. & $\mathrm{ARB}$ & 4 & Morfoesp \\
\hline Ageratum conyzoides $\mathrm{L}$. & ERV & 1 & Morfoesp \\
\hline Alomia fastigiata Benth. & ERV & 1 & Cas 1376 \\
\hline Ambrosia sp. & ARB & 1 & Pif 654 \\
\hline Baccharis dracunculifolia DC. & $\mathrm{ARB}$ & 1 & Pif 733 \\
\hline Baccharis schultzii Backer & ARB & 1,4 & Pif 664 \\
\hline Baccharis tridentata Gaudich. & $\mathrm{ARB}$ & 4 & Pif 736 \\
\hline Baccharis trimera (Less.) DC. & $\mathrm{ARB}$ & 1 & Cas 1384 \\
\hline Bidens segetum Mart. ex Colla & TREP & 1 & Pif 653 \\
\hline Bidens sp. & $\mathrm{ARB}$ & 4 & Pif 755 \\
\hline Chromolaena maximilianii (Schrader) R.M. King \& H. Rob. & $\mathrm{ARB}$ & 1 & Pif 746 \\
\hline Cosmos sp. & $\mathrm{ARB}$ & 1 & Pif 718 \\
\hline Cosmos sp2 & $\mathrm{ARB}$ & 1 & Val 470 \\
\hline Dasyphyllum spinescens (Less.) Cabrera & $\mathrm{ARB}$ & 4 & Cas 1378 \\
\hline Elephantopus mollis Kunth & ERV & 1,2 & Cas 1379 \\
\hline Emilia sonchifolia (L.) DC. & ERV & 1 & Cas 1426 \\
\hline Eremanthus erythropappus (DC.) MacLeish & ARV & 1,4 & Cas 1377 \\
\hline Eremanthus glomerulatus Less. & ARV & 1,4 & Pif 766 \\
\hline Eremanthus incanus (Less.) Less. & ARV & 1,4 & Pif 721 \\
\hline Eremanthus sp. & ARV & 4 & Cas 1383 \\
\hline Eupatorium sp. 1 & $\mathrm{ARB}$ & 1 & Pif 657 \\
\hline Eupatorium sp. 2 & $\mathrm{ARB}$ & 1 & Val 467 \\
\hline Galinsoga parviflora Cav. & ERV & 1 & Pif 703 \\
\hline Gochnatia polymorpha (Less.) Cabrera & ARV & 1 & Cas 1382 \\
\hline Heterocondylus alatus (Vell.) R.M. King \& H. Rob. & $\mathrm{ARB}$ & 1 & Pif 582 \\
\hline Hollophylla sp. & ERV & 4 & Pif 547 \\
\hline Mikania buddleiaefolia DC. & TREP & 1 & Cas 1381 \\
\hline Mikania sp. & TREP & 1 & Pif 681 \\
\hline Mikania sp.2 & TREP & 1 & Val 468 \\
\hline Mikania trichophila DC. & TREP & 1 & Pif 559 \\
\hline Piptocarpha axillaris (Less.) Baker & ARV & 1 & Val 369 \\
\hline
\end{tabular}


Tabela 1. Continuação...

\begin{tabular}{|c|c|c|c|}
\hline Família/Espécie & Hábito & Hábitats & Material testemunho \\
\hline Piptocarpha macropoda Baker & ARV & 1 & Pif 395 \\
\hline Sigesbeckia orientalis $\mathrm{L}$. & ERV & 1 & Pif 394 \\
\hline Sonchus oleraceus L. & ERV & 1 & Pif 387 \\
\hline Taraxacum officinale F.H. Wigg. & ERV & 1 & Morfoesp \\
\hline Trixis divaricata (Kunth) Spreng. & $\mathrm{ARB}$ & 1 & Morfoesp \\
\hline Verbesina glabrata Hook. \& Arn. & $\mathrm{ARB}$ & 1 & Pif 354 \\
\hline Vernonanthura divaricata (Spreng.) H.Rob. & ARV & 4 & Pif 730 \\
\hline Vernonia aurea Mart. ex DC. & $\mathrm{ARB}$ & 4 & Cas 1385 \\
\hline Vernonia polyanthes Less. & ARB & 4 & Cas 1387 \\
\hline Vernonia sp. & $\mathrm{ARB}$ & 1 & Morfoesp \\
\hline Wedellia paludosa & ERV & 3 & Cas 1386 \\
\hline Wulffia stenoglossa (Cass.) DC. & ARB & 1 & Pif 465 \\
\hline \multicolumn{4}{|l|}{ BALANOPHORACEAE } \\
\hline Langsdorffia hypogea Mart. & HOPA & 1 & Pif 652 \\
\hline \multicolumn{4}{|l|}{ BEGONIACEAE } \\
\hline Begonia digitata Raddi. & ERV & 2 & Cas 593 \\
\hline Begonia sp. & ERV & 2 & Morfoesp \\
\hline \multicolumn{4}{|l|}{ BIGNONIACEAE } \\
\hline Anemopaegma setilobum A.H.Gentry & TREP & 1 & Pif 396 \\
\hline Arrabidaea leucopogon (Cham.) Sandwith & TREP & 1 & Pif 510 \\
\hline Arrabidaea triplinervia ((Mart. ex DC.) Baill. ex Bureau. & TREP & 1 & Pif 524 \\
\hline Cybistax antisyphilitica (Mart.) Mart. & ARV & 1 & Cas 711 \\
\hline Fridericia speciosa Mart. & TREP & 1 & Cas 544 \\
\hline Jacaranda cuspidifolia Mart. ex A.DC. & ARV & 1 & Pif 728 \\
\hline Jacaranda macrantha Cham. & ARV & 1 & Pif 389 \\
\hline Jacaranda puberula Cham. & ARV & 1 & Cas 673 \\
\hline Dolichandra unguiscati (L.) L.G. Lohmann & TREP & 1 & Pif 569 \\
\hline Sparattosperma leucanthum (Vell.) K.Schum. & ARV & 1 & Cas 587 \\
\hline Tabebuia chrysotricha (Mart. ex A.DC.) Standl. & ARV & 1 & Cas 743 \\
\hline Tabebuia serratifolia (Vahl) Nichols & ARV & 1 & Cas 572 \\
\hline \multicolumn{4}{|l|}{ BLECHNACEAE } \\
\hline Blechnum brasiliense Desv. & ERV & 1 & Pif 714 \\
\hline Blechnum occidentale L. & ERV & 1 & Val 431 \\
\hline \multicolumn{4}{|l|}{ BORAGINACEAE } \\
\hline Cordia sellowiana Cham. & ARV & 1 & Cas 554 \\
\hline Cordia trichotoma (Vell.) Arrab. ex Steud. & ARV & 1 & Pif 745 \\
\hline Cordia sp. & ARV & 1 & Cas 1348 \\
\hline Boraginaceae sp. & ARV & 1 & Morfoesp \\
\hline \multicolumn{4}{|l|}{ BROMELIACEAE } \\
\hline Alcantarea sp. & EPI & 4 & Morfoesp \\
\hline Billbergia porteana Brongn ex.Beer & EPI & 4 & Pif 742 \\
\hline Dyckia saxatilis $\mathrm{Mez}$ & EPI & 4 & Morfoesp \\
\hline Tillandsia recurvata $(\mathrm{L}.) \mathrm{L}$. & EPI & 4 & Morfoesp \\
\hline Vriesea minarum L.B. Sm. & EPI & 4 & Morfoesp \\
\hline \multicolumn{4}{|l|}{ BURSERACEAE } \\
\hline Protium spruceanum (Benth.) Engl. & ARV & 2 & Cas 1430 \\
\hline \multicolumn{4}{|l|}{ CACTACEAE } \\
\hline Lepismium cruciforme (Vell.) Miq. & EPI & 1 & Val 454 \\
\hline \multicolumn{4}{|l|}{ CAMPANULACEAE } \\
\hline Siphocampylus sp. & $\mathrm{ARB}$ & 1 & Pif 660 \\
\hline
\end{tabular}


Tabela 1. Continuação...

\begin{tabular}{|c|c|c|c|}
\hline Família/Espécie & Hábito & Hábitats & Material testemunho \\
\hline \multicolumn{4}{|l|}{ CANNABACEAE } \\
\hline Celtis brasiliensis (Gardn.) Planch. & ARV & 1,2 & Cas 672 \\
\hline Trema micrantha (L.) Blume & ARV & 1 & Cas 729 \\
\hline \multicolumn{4}{|l|}{ CARDIOPTERIDACEAE } \\
\hline Citronella paniculata (Mart.) R.A.Howard & ARV & 1 & Pif 738 \\
\hline \multicolumn{4}{|l|}{ CASUARINACEAE } \\
\hline Casuarina equisetifolia $\mathrm{L}$. & ARV & 1 & Pif 678 \\
\hline \multicolumn{4}{|l|}{ CELASTRACEAE } \\
\hline Cheiloclinium cognatum (Miers.) A.C.Sm. & ARV & 2 & Val 287 \\
\hline Maytenus evonymoides Reissek & ARV & 1 & Pif 734 \\
\hline Maytenus ilicifolia Mart. & ARV & 1 & Pif 746 \\
\hline Maytenus salicifolia Reissek & ARV & 1 & Cas 777 \\
\hline Salacia elliptica (Mart. ex Schult.) G.Don & ARV & 2 & Morfoesp \\
\hline \multicolumn{4}{|l|}{ CHRYSOBALANACEAE } \\
\hline Hirtella gracilipes (Hook.f.) Prance & ARV & 1 & Cas 742 \\
\hline Hirtella hebeclada Moric. & ARV & 1 & Pif 758 \\
\hline Licania apetala (E.Mey.) Fritsch & ARV & 1 & Pif 622 \\
\hline Licania hoehnei Pilg. & ARV & 1 & Pif 574 \\
\hline Licania kunthiana Hook.f. & ARV & 1 & Val 447 \\
\hline \multicolumn{4}{|l|}{ CLETHRACEAE } \\
\hline Clethra scabra Pers. & ARV & 1 & Pif 748 \\
\hline \multicolumn{4}{|l|}{ CLUSIACEAE } \\
\hline Calophyllum brasiliense Cambess. & ARV & 2 & Morfoesp \\
\hline Garcinia brasiliensis Mart. & ARV & 1 & Cas 547 \\
\hline Kielmeyera petiolaris Mart. & ARV & 1 & Pif 648 \\
\hline \multicolumn{4}{|l|}{ COMBRETACEAE } \\
\hline Terminalia fagifolia Mart. & ARV & 1,4 & Pif 376 \\
\hline Terminalia glabrescens Mart. & ARV & 1 & Pif 737 \\
\hline \multicolumn{4}{|l|}{ COMMELINACEAE } \\
\hline Commelina sp. & ERV & 1 & Val 481 \\
\hline Commelina sp. 2 & ERV & 1 & Val 433 \\
\hline Dichorisandra sp. & ERV & 2 & Val 480 \\
\hline \multicolumn{4}{|l|}{ CONNARACEAE } \\
\hline Connarus beyrichii Planch. & ARV & 1 & Pif 722 \\
\hline \multicolumn{4}{|l|}{ CONVOLVULACEAE } \\
\hline Evolvulus sp. & TREP & 1 & Pif 499 \\
\hline Ipomoea nil (L.) Roth. & TREP & 1 & Val 483 \\
\hline Ipomoea purpurea (L.) Roth. & TREP & 1 & Pif 478 \\
\hline Ipomoea sp. 1 & TREP & 1 & Pif 687 \\
\hline Ipomoea sp. 2 & TREP & 1 & Val 473 \\
\hline Merremia macrocalyx (Ruiz ex Pav.) O’Donell & TREP & 1 & Pif 688 \\
\hline \multicolumn{4}{|l|}{ COSTACEAE } \\
\hline Costus spiralis (Jacq.) Roscoe & ERV & 2 & Pif 336 \\
\hline \multicolumn{4}{|l|}{ CUCURBITACEAE } \\
\hline Gurania sp. & TREP & 1 & Pif 763 \\
\hline Melothria sp. & TREP & 1 & Pif 571 \\
\hline Melothrianthus smilacifolius (Cogn.) Mart. Crov. & TREP & 1 & Pif 729 \\
\hline Momordica indica L. & TREP & 1 & Morfoesp \\
\hline Psiguria sp. & TREP & 1 & Morfoesp \\
\hline Wilbrandia hibiscoides Silva Manso & TREP & 1 & Pif 537 \\
\hline
\end{tabular}


Tabela 1. Continuação...

\begin{tabular}{|c|c|c|c|}
\hline Família/Espécie & Hábito & Hábitats & Material testemunho \\
\hline \multicolumn{4}{|l|}{ CUNONIACEAE } \\
\hline Lamanonia ternata Vell. & ARV & 1 & Pif 666 \\
\hline \multicolumn{4}{|l|}{ CYATHEACEAE } \\
\hline Cyathea atrovirens (Langsd.\& Fisch.) Domin & ERV.AR & 2 & Pif 725 \\
\hline Cyathea delgadii Sternb. & ERV.AR & 2 & Cas 1523 \\
\hline \multicolumn{4}{|l|}{ CYPERACEAE } \\
\hline Busbostylis sp. 1 & ERV & 3 & Pif 698 \\
\hline Busbostylis sp. 2 & ERV & 3 & Val 479 \\
\hline Cyperus aggregatus (Willd.) Endl. & ERV & 1 & Pif 749 \\
\hline Cyperus coriifolius Boeckeler & ERV & 1 & Cas 1507 \\
\hline Cyperus sp. & ERV & 1 & Pif 703 \\
\hline Cyperus sp. 2 & ERV & 4 & Val 503 \\
\hline Fuirena umbelatta Rottb. & ERV & 3 & Pif 702 \\
\hline Rhynchospora exaltata Kunth & ERV & 1 & Val 507 \\
\hline Ryncosphora sp. 1 & ERV & 4 & Pif 699 \\
\hline Ryncosphora sp. 2 & ERV & 4 & Pif 701 \\
\hline Ryncosphora sp. 3 & ERV & 4 & Pif 748 \\
\hline Scleria mitis P.J. Bergius & ERV & 1,2 & Pif 751 \\
\hline Scleria sp. & ERV & 1 & Val 505 \\
\hline Cyperaceae sp. & ERV & 3 & Pif 697 \\
\hline Cyperaceae sp. 2 & ERV & 3 & Pif 700 \\
\hline \multicolumn{4}{|l|}{ DILLENIACEAE } \\
\hline Davilla rugosa Poir. & TREP & 1 & Pif 342 \\
\hline \multicolumn{4}{|l|}{ DIOSCOREACEAE } \\
\hline Dioscorea sp. & TREP & 1 & Val 509 \\
\hline Dioscorea sp. 2 & TREP & 1 & Val 523 \\
\hline \multicolumn{4}{|l|}{ ELAEOCARPACEAE } \\
\hline Sloanea monosperma Vell. & ARV & 1 & Pif 749 \\
\hline \multicolumn{4}{|l|}{ ERICACEAE } \\
\hline Agarista glaberrima (Sleumer) Judd & ARV & 4 & Cas 1360 \\
\hline Gaylussacia brasiliensis (Spreng.) Mart. & ARV & 4 & Val 456 \\
\hline \multicolumn{4}{|l|}{ ERYTHROXYLACEAE } \\
\hline Erythroxylum pelleterianum A.St.-Hil. & ARV & 4 & Pif 733 \\
\hline \multicolumn{4}{|l|}{ EUPHORBIACEAE } \\
\hline Actinostemon klotzschii (Didr.) Pax & ARV & 1 & Cas 1498 \\
\hline Alchornea glandulosa Poepp. \& Endl. & ARV & 1 & Cas 741 \\
\hline Alchornea triplinervia (Spreng.) Müll.Arg. & ARV & 1 & Pif 673 \\
\hline Aparisthmium cordatum (Juss.) Baill. & ARV & 1 & Cas 770 \\
\hline Croton floribundus Spreng. & ARV & 1 & Pif 759 \\
\hline Croton lundianus (Didr.) Müll. Arg. & ERV & 1 & Val 465 \\
\hline Croton salutaris Casar. & ARV & 1 & Val 508 \\
\hline Croton urucuranus Baill. & ARV & 1 & Cas 722 \\
\hline Croton verrucosus Radcl.-Sm. \& Govaerts & ARV & 1 & Pif 619 \\
\hline Dalechampia tryphylla Lam. & TREP & 1 & Pif 427 \\
\hline Mabea fistulifera Mart. & ARV & 1 & Pif 674 \\
\hline Mabea pohliana (Benth.) Müll.Arg. & ARV & 1 & Cas 1535 \\
\hline Manihot grahamii Hook. & ARV & 1,4 & Cas 1504 \\
\hline Maprounea guianensis Aubl. & ARV & 1 & Pif 751 \\
\hline Pogonophora schomburgkiana Miers & ARV & 1 & Val 513 \\
\hline Sapium glandulosum (L.) Morong & ARV & 1 & Val 446 \\
\hline Sebastiania sp. & ARV & 4 & Morfoesp \\
\hline
\end{tabular}


Tabela 1. Continuação...

\begin{tabular}{|c|c|c|c|}
\hline Família/Espécie & Hábito & Hábitats & Material testemunho \\
\hline \multicolumn{4}{|l|}{ FABACEAE } \\
\hline Acacia polyphylla DC. & ARV & 1 & Cas 1514 \\
\hline Albizia niopoides (Spruce) Burkart & ARV & 1 & Morfoesp \\
\hline Andira fraxinifolia Benth. & ARV & 1 & Cas \\
\hline Andira paniculata Benth. & ARV & 4 & Pif 768 \\
\hline Bauhinia forficata Link & ARV & 1 & Val 472 \\
\hline Bauhinia longifolia (Bong.) D.Dietr. & ARV & 1 & Pif 746 \\
\hline Canavalia picta Mart. ex Benth. & TREP & 1 & Pif 748 \\
\hline Cassia ferruginea (Schrad.) Schrad. ex DC. & ARV & 1 & Val 463 \\
\hline Chamaecrista nictitans (L.) Moench. & ERV & 1 & Val 477 \\
\hline Cleobulia multiflora Mart. ex Benth. & TREP & 1 & Pif 693 \\
\hline Clitoria sp. & TREP & 4 & Val 466 \\
\hline Copaifera langsdorffii Desf. & ARV & 1 & Val 507 \\
\hline Crotalaria sp. & $\mathrm{ARB}$ & 4 & Pif 647 \\
\hline Dalbergia frutescens (Vell.) Britton & ARV & 1 & Pif 676 \\
\hline Dalbergia nigra (Vell.) Allemão ex Benth. & ARV & 1 & Pif 735 \\
\hline Dalbergia villosa (Benth.) Benth. & ARV & 1 & Morfoesp \\
\hline Desmodium sp. & ERV & 1 & Pif 485 \\
\hline Enterolobium contortisiliquum (Vell.) Morong & ARV & 1 & Val 497 \\
\hline Enterolobium timbouva Mart. & ARV & 2 & Morfoesp \\
\hline Indigofera suffruticosa Mill. & $\mathrm{ARB}$ & 1 & Cas 1547 \\
\hline Inga cylindrica (Vell.) Mart. & ARV & 2 & Morfoesp \\
\hline Inga edulis Mart. & ARV & 2 & Pif 784 \\
\hline Inga laurina (Sw.) Willd. & ARV & 1 & Morfoesp \\
\hline Inga marginata Willd. & ARV & 2 & Val 521 \\
\hline Inga platyptera Benth. & ARV & 2 & Morfoesp \\
\hline Lonchocarpus cultratus (Vell.) Az.-Tozzi \& H.C.Lima & ARV & 1 & Cas 1530 \\
\hline Machaerium acutifolium Vogel & ARV & 1 & Val 548 \\
\hline Machaerium brasiliense Vogel & ARV & 1 & Val 536 \\
\hline Machaerium dimorphandrum Hoehne & ARV & 1 & Pif 763 \\
\hline Machaerium hirtum (Vell.) Stellfeld & ARV & 1 & Pif 463 \\
\hline Machaerium nictitans (Vell.) Benth. & ARV & 1 & Val 336 \\
\hline Machaerium villosum Vogel & ARV & 1 & Cas 1563 \\
\hline Melanoxylon brauna Schott & ARV & 1 & Cas 1401 \\
\hline Mimosa velloziana Mart. & $\mathrm{ARB}$ & 1 & Pif 691 \\
\hline Piptadenia gonoacantha (Mart.) J.F.Macbr. & ARV & 1 & Val 540 \\
\hline Piptadenia sp. & TREP & 1 & Pif 690 \\
\hline Platypodium elegans Vogel & ARV & 1 & Pif 475 \\
\hline Pseudopiptadenia warmingii (Benth.) G.P.Lewis \& M.P.Lima & ARV & 1 & Morfoesp \\
\hline Senna cana (Nees \& Mart.) H.S.Irwin \& Barneby & ARV & 4 & Morfoesp \\
\hline Senna macranthera (Collad.) H.S.Irwin \& Barneby & ARV & 1 & Val 474 \\
\hline Senna multijuga (L.C.Rich.) H.S.Irwin \& Barneby & ARV & 1 & Val 363 \\
\hline Senna sp. & $\mathrm{ARB}$ & 1 & Val 475 \\
\hline Stryphnodendron polyphyllum Mart. & ARV & 1 & Pif 692 \\
\hline Stylosanthes sp. & ERV & 1 & Val 476 \\
\hline Swartzia apetala Raddi & ARV & 1 & Pif 741 \\
\hline Swartzia multijuga Hayne & ARV & 2 & Val 511 \\
\hline Swartzia sp. & ARV & 1 & Val 356 \\
\hline Tachigali denudata (Vogel) Oliveira Filho & ARV & 1 & Cas 1430 \\
\hline Tachigali rugosa (Mart. ex Benth.) Zarucchi \& Pipoly & ARV & 1 & Cas 1406 \\
\hline Fabaceae indet. 1 & TREP & 1 & Pif 675 \\
\hline
\end{tabular}


Tabela 1. Continuação...

\begin{tabular}{|c|c|c|c|}
\hline Família/Espécie & Hábito & Hábitats & Material testemunho \\
\hline Fabaceae indet. 2 & TREP & 1 & Pif 694 \\
\hline \multicolumn{4}{|l|}{ GENTIANACEAE } \\
\hline Irlbachia sp. & ERV & 4 & Cas 1371 \\
\hline \multicolumn{4}{|l|}{ HUMIRIACEAE } \\
\hline Sacoglottis guianensis Malme & ARV & 1 & Pif 774 \\
\hline \multicolumn{4}{|l|}{ HYMENOPHYLLACEAE } \\
\hline Hymenophyllum sp. & ERV & 2 & Morfoesp \\
\hline \multicolumn{4}{|l|}{ HYPERICACEAE } \\
\hline Vismia guianensis (Aubl.) Pers. & ARV & 1 & Val 461 \\
\hline Vismia magnoliifolia Schltdl. \& Cham & ARV & 1 & Pif 564 \\
\hline \multicolumn{4}{|l|}{ INDETERMINADA } \\
\hline Indeterminada sp. 1 & ARV & 1 & Cas 1531 \\
\hline Indeterminada sp. 2 & ARV & 1 & Pif 587 \\
\hline \multicolumn{4}{|l|}{ LACISTEMATACEAE } \\
\hline Lacistema hasslerianum Chodat & ARV & 1 & Pif 463 \\
\hline Lacistema pubescens Mart. & ARV & 1 & Pif 434 \\
\hline \multicolumn{4}{|l|}{ LAMIACEAE } \\
\hline Aegiphila sellowiana Cham. & ARV & 1 & Cas 1364 \\
\hline Hyptidendron asperrimum (Epling) Harley & ARV & 1 & Cas 1377 \\
\hline Hyptis coriacea Benth. & $\mathrm{ARB}$ & 4 & Pif 667 \\
\hline Hyptis rhypidiophylla Briq. & $\mathrm{ARB}$ & 4 & Pif 668 \\
\hline Vitex megapotamica (Spreng.) Moldenke & ARV & 1 & Val 524 \\
\hline Vitex polygama Cham. & ARV & 4 & Pif 578 \\
\hline Lamiaceae indet. 1 & ARB & 1 & Pif 669 \\
\hline Lamiaceae indet. 2 & $\mathrm{ARB}$ & 1 & Pif 670 \\
\hline \multicolumn{4}{|l|}{ LAURACEAE } \\
\hline Aiouea saligna Meisn. & ARV & 1 & Pif 467 \\
\hline Aniba firmula (Nees \& Mart.) Mez & ARV & 1 & Val 459 \\
\hline Endlicheria paniculata (Spreng.) J.F.Macbr. & ARV & 1 & Cas 1488 \\
\hline Nectandra lanceolata Nees & ARV & 1 & Cas 1511 \\
\hline Nectandra membranacea (Sw.) Griseb. & ARV & 1 & Pif 744 \\
\hline Nectandra nitidula Nees & ARV & 2 & Pif 763 \\
\hline Nectandra oppositifolia Nees & ARV & 1 & Val 528 \\
\hline Ocotea aciphylla (Nees) Mez & ARV & 1 & Cas 1354 \\
\hline Ocotea bicolor Vattino & ARV & 1 & Val 433 \\
\hline Ocotea brachybotrya (Meisn.) Mez & ARV & 1 & Val 512 \\
\hline Ocotea diospyrifolia (Meisn.) Mez & ARV & 2 & Pif 741 \\
\hline Ocotea lancifolia (Schott) Mez & ARV & 1,2 & Pif 479 \\
\hline Ocotea laxa (Nees) Mez & ARV & 1 & Pif 397 \\
\hline Ocotea minarum (Nees) Mez & ARV & 1 & Morfoesp \\
\hline Ocotea odorifera (Vell.) Rohwer & ARV & 1 & Cas 1537 \\
\hline Ocotea pomaderroides (Meisn.) Mez & ARV & 4 & Pif 763 \\
\hline Persea major (Nees) L.E. Kopp & ARV & 1 & Cas 1375 \\
\hline Persea rufotomentosa Nees \& C. Mart. & ARV & 1 & Cas 1364 \\
\hline \multicolumn{4}{|l|}{ LECYTHIDACEAE } \\
\hline Cariniana estrellensis (Raddi) Kuntze & ARV & 2 & Pif 730 \\
\hline Lecythis pisonis Cambess. & ARV & 1 & Morfoesp \\
\hline \multicolumn{4}{|l|}{ LOGANIACEAE } \\
\hline Spigelia schlechtendaliana Mart. & $\mathrm{ARB}$ & 4 & Morfoesp \\
\hline \multicolumn{4}{|l|}{ LORANTHACEAE } \\
\hline Struthanthus concinnus Mart. & H.PAR & 1 & Pif 346 \\
\hline
\end{tabular}


Tabela 1. Continuação...

\begin{tabular}{|c|c|c|c|}
\hline Família/Espécie & Hábito & Hábitats & Material testemunho \\
\hline Struthanthus marginatus (Desr.) Blume & H.PAR & 1 & Pif 644 \\
\hline \multicolumn{4}{|l|}{ LYTHRACEAE } \\
\hline Cuphea sp. & $\mathrm{ARB}$ & 3 & Cas 1363 \\
\hline Lafoensia pacari A.St.-Hil. & ARV & 1,4 & Pif 651 \\
\hline \multicolumn{4}{|l|}{ MALPIGHIACEAE } \\
\hline Byrsonima intermedia A.Juss. & ARV & 1,4 & Cas 1505 \\
\hline Banisteriopsis salicifolia (DC.) B.Gates & TREP & 4 & Val 484 \\
\hline Byrsonima laxiflora Griseb. & ARV & 1,4 & Pif 717 \\
\hline Byrsonima sericea DC. & ARV & 4 & Cas 1401 \\
\hline Byrsonima verbascifolia (L.) DC. & ARV & 1,4 & Val 420 \\
\hline Heteropterys byrsonimifolia A.Juss. & ARV & 4 & Pif 754 \\
\hline Heteropterys umbellata A. Juss. & TREP & 4 & Pif 733 \\
\hline Peixotoa tomentosa A. Juss. & $\mathrm{ARB}$ & 4 & Val 491 \\
\hline \multicolumn{4}{|l|}{ MALVACEAE } \\
\hline Abutilon rufinerve A.St.-Hil. & $\mathrm{ARB}$ & 4 & Cas 1414 \\
\hline Eriotheca candolleana (K.Schum.) A.Robyns & ARV & 1 & Cas 1497 \\
\hline Eriotheca macrophylla (K.Schum.) A.Robyns & ARV & 1 & Pif 745 \\
\hline Hibiscus sp. & $\mathrm{ARB}$ & 4 & Pif 684 \\
\hline Luehea candicans Mart. \& Zucc. & ARV & 1,4 & Cas 1297 \\
\hline Luehea divaricata Mart. \& Zucc. & ARV & 1 & Cas 1462 \\
\hline Luehea grandiflora Mart. \& Zucc. & ARV & 1 & Cas 1359 \\
\hline Luehea paniculata Mart. \& Zucc. & ARV & 1 & Pif 768 \\
\hline Pavonia sp. & $\mathrm{ARB}$ & 1 & Pif 685 \\
\hline Pseudobombax endecaphyllum (Vell.) A.Robyns & ARV & 1 & Pif 483 \\
\hline Sida carpinifolia $\mathrm{L}$. & $\mathrm{ARB}$ & 1 & Pif 647 \\
\hline Sida sp. & ERV & 1 & Pif 658 \\
\hline Triumfetta semitriloba Jacq. & $\mathrm{ARB}$ & 1 & Val 471 \\
\hline Waltheria indica $\mathrm{L}$. & $\mathrm{ARB}$ & 1 & Pif 677 \\
\hline Waltheria sp. & $\mathrm{ARB}$ & 1 & Pif 689 \\
\hline Malvaceae indet. & $\mathrm{ARB}$ & 1 & Pif 659 \\
\hline \multicolumn{4}{|l|}{ MARANTACEAE } \\
\hline Calathea sp. & ERV & 2 & Pif 631 \\
\hline \multicolumn{4}{|l|}{ MELASTOMATACEAE } \\
\hline Chaetostoma sp. & $\mathrm{ARB}$ & 1,2 & Cas 1539 \\
\hline Clidemia hirta (L.) D. Don & $\mathrm{ARB}$ & 1,4 & Cas 1397 \\
\hline Huberia laurina DC. & ARV & 2 & Cas 1536 \\
\hline Leandra dasytricha (A.Gray) Cogn. & $\mathrm{ARB}$ & 1 & Val 566 \\
\hline Leandra sericea DC. & $\mathrm{ARB}$ & 1 & Val 364 \\
\hline Leandra xanthostachya Cogn. & $\mathrm{ARB}$ & 1 & Cas 1564 \\
\hline Miconia argyrophylla DC. & ARV & 1 & Pif 756 \\
\hline Miconia cf. petropolitana Cogn. & ARV & 1 & Pif 630 \\
\hline Miconia chartacea Triana & ARV & 1 & Cas 1397 \\
\hline Miconia cinnamomifolia (DC.) Naudin & ARV & 1 & Cas 1395 \\
\hline Miconia latecrenata (DC.) Naudin & ARV & 1 & Val 496 \\
\hline Miconia rubiginosa (Bonpl.) DC. & ARV & 4 & Val 516 \\
\hline Miconia sellowiana Naudin & ARV & 1 & Pif 739 \\
\hline Miconia sp. 1 & ARV & 1 & Pif 686 \\
\hline Miconia sp. 2 & ARV & 1 & Cas 1394 \\
\hline Ossaea amygdaloides (Mart. \& Schr.) Triana & TREP & 2 & Val 551 \\
\hline Tibouchina arborea (Gardn.) Cogn. & ARV & 1 & Pif 593 \\
\hline Tibouchina pulchra Cogn. & ARB & 1 & Pif 742 \\
\hline
\end{tabular}


Tabela 1. Continuação...

\begin{tabular}{|c|c|c|c|}
\hline Família/Espécie & Hábito & Hábitats & Material testemunho \\
\hline Tibouchina multiflora Cogn. & $\mathrm{ARB}$ & 4 & Cas 1393 \\
\hline Melastomataceae indet. 1 & $\mathrm{ARB}$ & 3 & Cas 1388 \\
\hline Melastomataceae indet. 2 & $\mathrm{ARB}$ & 3 & Cas 1389 \\
\hline Melastomataceae indet. 3 & $\mathrm{ARB}$ & 3 & Cas 1390 \\
\hline Melastomataceae indet. 4 & $\mathrm{ARB}$ & 3 & Cas 1391 \\
\hline Melastomataceae indet. 5 & $\mathrm{ARB}$ & 3 & Cas 1392 \\
\hline \multicolumn{4}{|l|}{ MELIACEAE } \\
\hline Cabralea canjerana (Vell.) Mart. & ARV & 1 & Pif 580 \\
\hline Cedrela fissilis Vell. & ARV & 1 & Pif 650 \\
\hline Guarea macrophylla Vahl & ARV & 2 & Val 549 \\
\hline \multicolumn{4}{|l|}{ MENISPERMACEAE } \\
\hline Abuta selloana Eichler & TREP & 1 & Pif 364 \\
\hline Chondrodendron platiphyllum (A.St.-Hil.) Miers & TREP & 1 & Val 427 \\
\hline Cissampelos glaberrima A.St.-Hil. & TREP & 1 & Cas 1366 \\
\hline \multicolumn{4}{|l|}{ MONIMIACEAE } \\
\hline Mollinedia argyrogyna Perkins & ARV & 1 & Pif 770 \\
\hline Mollinedia widgrenii A.DC. & ARV & 1 & Pif 610 \\
\hline \multicolumn{4}{|l|}{ MORACEAE } \\
\hline Brosimum guianense (Aubl.) Huber & ARV & 1 & Pif 603 \\
\hline \multicolumn{4}{|l|}{ SCHIZAEACEAE } \\
\hline Ligodium venustum $\mathrm{Sw}$. & TREP & 2 & Pif 615 \\
\hline \multicolumn{4}{|l|}{ SIMAROUBACEAE } \\
\hline Simarouba amara Aubl. & ARV & 1 & Cas 1324 \\
\hline Simarouba versicolor A.St.-Hil. & ARV & 4 & Morfoesp \\
\hline \multicolumn{4}{|l|}{ SIPARUNACEAE } \\
\hline Siparuna cujabana (Mart.) A.DC. & ARV & 1 & Cas 1352 \\
\hline Siparuna guianensis Aubl. & ARV & 1 & Pif 775 \\
\hline \multicolumn{4}{|l|}{ SMILACACEAE } \\
\hline Smilax brasiliensis Spreng. & TREP & 1 & Val 487 \\
\hline Smilax campestris Griseb. & TREP & 1 & Pif 646 \\
\hline Smilax sp. & TREP & 4 & Cas 1545 \\
\hline \multicolumn{4}{|l|}{ SOLANACEAE } \\
\hline Aureliana fasciculata var. tomentella (Sendtn.) Barbosa \& Huntz. & $\mathrm{ARB}$ & 1 & Pif 777 \\
\hline Brunfelsia brasiliensis (Spreng.) L.B. Sm. \& Downs & $\mathrm{ARB}$ & 1 & Cas 1355 \\
\hline Cestrum amictum Schltdt. & $\mathrm{ARB}$ & 1 & Morfoesp \\
\hline Dyssochroma viridiflora (Sims) Miers & $\mathrm{ARB}$ & 2 & Morfoesp \\
\hline Solanum bullatum Vell. & ARV & 1 & Morfoesp \\
\hline Solanum leucodendron Sendtn. & ARV & 1 & Cas 1546 \\
\hline Solanum paniculatum $\mathrm{L}$. & ARV & 1 & Val 499 \\
\hline Solanum pseudoquina A.St.-Hil. & ARV & 1 & Cas 1354 \\
\hline Solanum sp. 1 & $\mathrm{ARB}$ & 1 & Cas 1353 \\
\hline Solanum sp. 2 & $\mathrm{ARB}$ & 1 & Cas 1356 \\
\hline Solanum swartzianum Roem. \& Schult. & ARV & 1 & Cas 1317 \\
\hline Solanum velleum Thunb. & ARV & 1 & Pif 776 \\
\hline \multicolumn{4}{|l|}{ STYRACACEAE } \\
\hline Styrax camporum Pohl & ARV & 1 & Cas 1548 \\
\hline Styrax latifolius Pohl & ARV & 2 & Pif 760 \\
\hline Styrax pohlii A.DC. & ARV & 1 & Val 554 \\
\hline \multicolumn{4}{|l|}{ SYMPLOCACEAE } \\
\hline Symplocos mosenii Brand & ARV & 4 & Val 557 \\
\hline
\end{tabular}


Tabela 1. Continuação...

\begin{tabular}{|c|c|c|c|}
\hline Família/Espécie & Hábito & Hábitats & Material testemunho \\
\hline \multicolumn{4}{|l|}{ THYMELAEACEAE } \\
\hline Daphnopsis fasciculata (Meisn.) Nevling & ARV & 1 & Pif 761 \\
\hline \multicolumn{4}{|l|}{ URTICACEAE } \\
\hline Cecropia glaziovi Snethl. & ARV & 1 & Cas 1323 \\
\hline Cecropia hololeuca Miq. & ARV & 1 & Morfoesp \\
\hline Cecropia pachystachya Trécul & ARV & 1 & Val 502 \\
\hline Hemistylus sp. & ARV & 2,4 & Cas 1333 \\
\hline Urera nitida (Vell.) Brack & $\mathrm{ARB}$ & 1 & Morfoesp \\
\hline \multicolumn{4}{|l|}{ VELLOZIACEAE } \\
\hline Barbacenia flava Mart. ex Schult. \& Schult. f. & ERV & 4 & Cas 1367 \\
\hline Barbacenia exscapa Mart. & ERV & 4 & Cas 1549 \\
\hline \multicolumn{4}{|l|}{ VERBENACEAE } \\
\hline Aloysia virgata (Ruiz \& Pav.) A.Juss. & ARV & 1,2 & Pif 762 \\
\hline Citharexylum myrianthum Cham. & ARV & 1 & Morfoesp \\
\hline Lantana brasiliensis Link & $\mathrm{ARB}$ & 1 & Morfoesp \\
\hline Lantana camara $\mathrm{L}$. & $\mathrm{ARB}$ & 1 & Pif 682 \\
\hline Lantana fucata Lindl. & $\mathrm{ARB}$ & 1 & Pif 672 \\
\hline Lippia sidoides Cham. & $\mathrm{ARB}$ & 4 & Val 458 \\
\hline Stachytarpheta reticulata Mart. ex Schauer & ARB & 4 & Pif 679 \\
\hline Stachytarpheta cajanensis Vahl & $\mathrm{ARB}$ & 1 & Pif 671 \\
\hline \multicolumn{4}{|l|}{ VIOLACEAE } \\
\hline Anchietea pyrifolia A.St.-Hil. & TREP & 1 & Pif 767 \\
\hline Hybanthus brevicaulis (Mart.) Taub. & $\mathrm{ARB}$ & 1,2 & Cas 1405 \\
\hline \multicolumn{4}{|l|}{ VITACEAE } \\
\hline Cissus sp. & TREP & 1 & Morfoesp \\
\hline Cissus sulcicaulis (Baker) Planch. & TREP & 1 & Cas 1332 \\
\hline \multicolumn{4}{|l|}{ VOCHYSIACEAE } \\
\hline Callisthene fasciculata (Spreng.) Mart. & ARV & 1 & Pif 443 \\
\hline Callisthene major Mart. & ARV & 1 & Cas 1566 \\
\hline Callisthene minor Mart. & ARV & 4 & Cas 1550 \\
\hline Qualea cordata (Mart.) Spreng. & ARV & 1 & Pif 769 \\
\hline Qualea dichotoma (Mart.) Warm. & ARV & 4 & Morfoesp \\
\hline Qualea selloi Warm. & ARV & 1 & Morfoesp \\
\hline Qualea sp. & ARV & 1 & Cas 1368 \\
\hline Vochysia cf. pyramidalis Mart. & ARV & 4 & Pif 388 \\
\hline Vochysia cinnamomea Pohl & ARV & 4 & Cas 1366 \\
\hline Vochysia magnifica Warm. & ARV & 1 & Morfoesp \\
\hline \multicolumn{4}{|l|}{ ZINGIBERACEAE } \\
\hline Hedychium coronarium J. König & ERV & 3 & Val 556 \\
\hline
\end{tabular}

Vriesea sp. De forma geral, o sub-bosque encontrava-se bastante iluminado com a ocorrência de grupos que o caracterizam em formações semideciduais como Geonoma schottiana Mart., Psychotria carthagenensis Jacq., Psychotria cephalantha (Müll.Arg.) Standl., Psychotria nuda (Cham. \& Schltdl.) Wawra, Psychotria suterella Müll.Arg., Psychotria vellosiana Benth. e Rudgea jasminoides (Cham.) Müll.Arg. Foram encontradas 426 espécies pertencentes a 83 famílias nessa formação (Tabela 2). As famílias com maior número de espécies foram: Fabaceae (40), Asteraceae (30), Myrtaceae (30), Rubiaceae (21) e Euphorbiaceae (15). A distribuição das espécies nos hábitos indicou predomínio das árvores em relação aos demais, sendo os mais representativos: Arbóreo (314), Herbáceo (30), Trepador (20), Arbustivo (18) e Epifítico (dois). É importante mencionar que em todos os fragmentos houve ocorrência de árvores consideradas de madeira nobre, como os respectivos casos da braúna (Melanoxylon brauna Schott - Fabaceae) e do jequitibá (Cariniana estrellensis (Raddi) Kuntze - Lecythidaceae).

As Matas Ciliares foram encontradas em faixas estreitas margeando os pequenos rios da região compondo crca de $5 \%$ da vegetação local em área. Essa formação inicia-se em depressões (nos fundos de vale constituindo talvegues) de encostas, onde a água das nascentes é canalizada em cursos d'água alimentando córregos. Nesses locais, há contato direto das formações ciliares com a Floresta Montana, e sua composição florística é diversificada e também marcada pela ocorrência de espécies exclusivas desses locais mais úmidos, como Cyathea atrovirens (Langsd. \& Fisch.) Domin e Cyathea delgadii 
Tabela 2. Número de famílias, gêneros e espécies exclusivas amostradas nas fitofisionomias da Serra do Condado, Serro, MG, Brasil. FESM= Floresta Estacional Semidecidual Montana; $\mathrm{MC}=$ Mata Ciliar; $\mathrm{AC}=$ Vegetação Arbustivo-lenhosa sobre Canga; $\mathrm{BJ}=$ Brejo.

Table 2. Number of exclusive families, genera and species sampled in the phytophysiognomic at Range mountain of the Serro County, MG, Brazil. FESM= Montane Semidecidual Atlantic Forest; $\mathrm{MC}=$ Riverine Forest; $\mathrm{AC}=$ Woody-Shrub vegetation on Canga; $\mathrm{BJ}=$ Swamp.

\begin{tabular}{ccccc}
\hline Fitofisionomia & Famílias & Gêneros & Espécies & Exclusivas \\
\hline FESM & 83 & 253 & 426 & 391 \\
MC & 28 & 57 & 74 & 54 \\
BJ & 7 & 10 & 19 & 18 \\
AC & 29 & 78 & 94 & 71 \\
\hline
\end{tabular}

Tabela 3. Índice de similaridade de Sørensen (\%) entre as fitofisionomias da Serra do Condado, Serro, MG, Brasil. FESM= Floresta Estacional Semidecidual Montana; $\mathrm{MC}=$ Mata Ciliar; $\mathrm{AC}=$ Vegetação Arbustivo- lenhosa sobre Canga Canga; $\mathrm{BJ}=$ Brejo.

Table 3. Percentage values of Sørensen similarity index between phytophysiognomics at Range mountain of the Serro County, MG, Brazil. FESM $=$ Montane Semidecidual Atlantic Forest; $\mathrm{MC}=$ Riverine Forest; $\mathrm{AC}=$ Woody-Shrub vegetation on Canga; $\mathrm{BJ}=$ Swamp .

\begin{tabular}{lcccc}
\hline & FESM & MC & BJ & AC \\
\hline FESM & 100 & 5,20 & 0,45 & 6,92 \\
MC & - & 100 & 0 & 3,57 \\
BJ & - & - & 100 & 0 \\
AC & - & - & - & 100 \\
\hline
\end{tabular}

Sternb. Onde a Mata Ciliar está em contato com pastagens ou estradas, a composição florística é pobre, com abundância de Inga edulis Mart. e Matayba guianensis Aubl. O sub-bosque dessa formação apresentou-se pobre com a predominância de Celtis brasiliensis (Gardn.) Planch. em relação às demais árvores deste estrato. Foram encontradas 74 espécies pertencentes a 28 famílias (Tabela 2). As famílias com maior número de espécies foram: Fabaceae (sete), Piperaceae (quatro) e Annonaceae (três).

Os brejos ocuparam apenas $2 \%$ de toda a área e estão localizados em planícies no fundo dos vales, com solo pedregoso de difícil drenagem, sendo algumas das nascentes e cursos d'água responsáveis pela manutenção perene dos mesmos. A saturação hídrica constante é um evento seletivo da peculiar composição florística dessa formação. Das 19 espécies encontradas, 18 foram exclusivas e apenas uma (Asclepias curassavica L.) foi compartilhada com a Mata Ciliar (Tabela 2). As famílias com maior número de espécies foram: Cyperaceae (cinco), Melastomataceae (cinco), Onagraceae (três) e Ochnaceae (duas). Alguns gêneros como Cyperus (Cyperaceae) e Ludwigia (Onagraceae) merecem destaque pela riqueza obtida em todos os brejos estudados.

As formações sobre canga cobriram cerca de $13 \%$ da área de estudo e apresentaram substrato rochoso, rico em hematita, com a formação de solos rasos nas suas pequenas depressões. A vegetação é arbustivo-lenhosa de baixa estatura, não ultrapassando $5 \mathrm{~m}$ de altura, com cobertura uni-estratificada. Houve a presença proporcionalmente abundante de espécies herbáceas de campo rupestre (Velloziaceae, Eriocaulaceae, Orchidaceae, Bromeliaceae, Gentianaceae, Melastomataceae, etc.), além das poucas árvores também relacionadas com solos litólicos (Eremanthus spp., Gaylussacia brasiliensis (Spreng.) Mart. e Coccoloba cerifera Schwacke). Nos locais de menor altitude e com a formação de um solo de maior profundidade, observou-se a formação de manchas de solo orgânico que permitiram o estabelecimento de espécies de porte mais elevado e de ocorrência florestal (Pera glabrata (Schott) Poepp. ex Baill., Andira paniculata Benth., Calyptranthes clusiifolia O.Berg, Myrceugenia ovalifolia (O.Berg) Landrum, Myrcia guianensis (Aubl.) DC., etc.) constituindo uma fronteira física entre a Floresta Montana e a Vegetação Arbustiva-Lenhosa sobre Canga. Foram encontradas nessa formação 94 espécies distribuídas em 29 famílias (Tabela 2). As famílias com maior número de espécies foram: Asteraceae (nove), Orchidaceae (sete), Bromeliaceae (cinco), Apocynaceae (cinco) e Vochysiaceae (quatro).

A similaridade florísitica entre as fitofisionomias da Serra do Condado é baixa. Este fato é comprovado pela grande quantidade de espécies exclusivas de cada formação (Tabela 2) e pelas estimativas do índice de Sørensen, expressos na Tabela 3. A maior similaridade encontrada foi relacionanda à Floresta Estacional Semidecidual Montana e a Vegetação Arbustivo-Lenhosa sobre Canga (aproximadamente $0,0692 \%$ ), porém este ainda é considerado muito baixo (inferior a 0,5 ).

\section{Discussão}

A Serra do Condado é um mosaico vegetacional com predominância da Formação Estacional Semidecidual Montana em relação à Canga, a Mata Ciliar e ao Brejo. O limite físico entre fitofisionomias foi gradual ou constante sendo difícil individualizar até mesmo algumas zonas ecotonais, embora considerando a paisagem como um todo, seja possível separar cada formação. E assim, é nítido que a altitude e o solo litólico têm estreita relação com as formações de Canga, sendo observadas sempre nos afloramentos acima dos $900 \mathrm{~m}$ de altitude. Em cotas inferiores há uma expansão da Formação Semidecidual Montana no solo litólico, uma fitocenose de estrutura densa (varal), baixa dominância e alto perfilhamento dos indivíduos eretos e lenhosos. Esse cenário suporta espécies florestais tolerantes a esse substrato sendo essas gradativamente substituídas pelas candeias (Erementhus spp.) com o aumento da altitude (obs. pess.). Considerando levantamentos florísticos que contemplam todas as formas de vida em áreas do Domínio Atlântico representado pelas Florestas Estacionais e Ombrófilas a riqueza encontrada neste estudo (575 espécies) está próxima do registrado por Lombardi \& Gonçalves (2000) no Parque Estadual do Rio Doce (535) e está abaixo do registrado para algumas áreas ombrófilas do Rio de Janeiro e de São Paulo como Parati (Marques 1997) com 873 espécies, Macaé de Cima (Lima \& Guedes-Bruni 1997) com 946 espécies e Ilha do Cardoso (Melo et al. 1991) com 852. É importante ressaltar que em todos os trabalhos acima comparados, o esforço de coleta foi superior a três anos e isso, em partes, justifica tais diferenças. Outra questão pertinente a ser abordada é em relação ao número de materiais indeterminados do presente trabalho (116 ou $20 \%$ do total). Este valor aparentemente alto de indeterminações pode ser explicado pela necessidade de mais trabalhos taxonômicos capazes de fornecer um maior número de floras e revisões, já que para alguns grupos existe ainda carência de bibliografias especializadas.

Ainda considerando a flora da Serra do Condado como um todo é possível destacar a ocorrência de algumas espécies consideradas ruderais como Alomia fastigiata Benth., Elephantopus mollis Kunth, Emilia sonchifolia (L.) DC., Galinsoga parviflora Cav., Sigesbeckia orientalis L. e Waltheria indica L., dentre outras. Este fato mostra o quanto as áreas de pastagem avançam sobre as áreas florestais e de campos naturais, refletindo na supressão de hábitats observada em toda a Serra. Em adição, segundo Giulietti et al. (2008), a Cadeia do Espinhaço é uma das regiões que concentram grande número de endemismos e espécies consideradas raras sendo algumas destas últimas também registradas nesse estudo como Hyptis coriacea Benth., Hyptis rhypidiophylla Briq. e Barbacenia exscapa Mart. Outras são 
consideradas como indicadoras de Complexos Rupestres de Altitude como Agarista glaberrima (Sleumer) Judd, Gaylussacia brasiliensis (Spreng.) Mart., Barbacenia flava Mart. ex Schult. \& Schult. f., Mandevilla scabra (Roem. \& Schult.) K. Schum., Stipecoma peltigera (Staldem.) Mull.Arg., Eremanthus erythropappus (DC.) MacLeish, Eremanthus glomerulatus Less. e Eremanthus incanus (Less.) Less. (Benites et al. 2003). Cabe salientar que as espécies acima aludidas foram registradas preferencialmente na Vegetação Arbustivo-lenhosa sobre Canga justificando assim sua prioridade de conservação.

Em relação às áreas de Floresta Estacional Semidecidual observou-se um predomínio do hábito arbóreo em relação aos demais sendo este fato também relatado para outros levantamentos florísticos completos em Minas Gerais (todas as formas de vida) como no Morro do Imperador (Pifano et al. 2007), no Parque Estadual do Rio Doce e na Estação Ecológica de Caratinga (Lombardi \& Gonçalves 2000). Isto pode ser explicado pela grande ocorrência de espécies arbóreas de sub-bosque e subdossel que apresentam estruturas reprodutivas por longos períodos do ano, facilitando sua visualização e consequentemente sua coleta. Como a maioria das formações do estado é secundária (Scolforo \& Carvalho 2006) o sub-bosque é bastante iluminado nessas florestas e isso também ajuda na compreensão deste estágio fenológico apresentado por seus elementos.

A elevada riqueza de árvores encontradas na Floresta Estacional Semidecidual Montana (314) corrobora com os resultados de outros levantamentos florístico-estruturais em Florestas Montanas do Domínio Atlântico de Minas Gerais. Pereira et al. (2006), com o trabalho realizado no maciço do Itatiaia, registrou 450 espécies de árvores e Oliveira-Filho et al. (2004), na Chapada das Perdizes, Carrancas, MG, registrou 218, mostrando valores de riqueza intermediários em comparação com o deste estudo. Porém, na Estação Ecológica do Tripuí, Ouro Preto, MG (Werneck et al. 2000), a riqueza encontrada (68) foi muito menor, sendo este fato justificado pelo esforço amostral discrepante quando se compara os dois trabalhos, já que o estudo de Werneck et al. (2000) se constituiu de um levantamento estrutural da vegetação contemplando apenas $900 \mathrm{~m}^{2}$ de área amostrada sob a forma de parcelas. As Matas Ciliares em melhor estado de conservação são raras e fisionomicamente indistintas das Florestas Montanas circunvizinhas, sendo possível diferenciá-las apenas por composição florística. Algumas árvores de grande porte como Ficus gomelleira Kunth \& Bouché e Calophyllum brasiliense Cambess. são indícios da idade avançada e da aparente ausência de pertubação desses trechos na formação (Rodrigues \& Naves 2000). Esse estágio sucessional é importante para a conservação da área de estudo sendo justificado por tal conexão entre esses hábitats, o que dificulta o acesso de pessoas e do gado e consequentemente auxilia na manutenção da qualidade e quantidade da água de toda a microbacia (Alvarenga \& Paula 2000). A manutenção desses trechos é fundamental também para a conservação de algumas espécies de Acanthaceae (Herpetacanthus rubiginosos Nees) e Marantaceae (Calathea sp.), que só foram encontradas em seu sub-bosque úmido. Já nos trechos onde os rios cortam os biótopos antropizados, a Mata Ciliar apresenta-se constantemente perturbada em função do uso inadequado do solo para atividades agropastoris (Pereira 2003).

Todos os brejos estudados encontram-se isolados e desconectados de quaisquer fragmentos de Floresta Montana ou Mata Ciliar. Este fato pôde ser comprovado através da baixa riqueza florística dessa formação (apenas 19 espécies) em comparação com a alta diversidade de macrófitas relacionadas às formações brejosas segundo os trabalhos de Hoehne (1948) e Pott, A. \& Pott, V.J. (2000). Ainda assim, a exclusividade específica foi a mais alta entre todas as fitofisionomias estudadas (95\%), agregando valor imediato de conservação para essa formação.
Segundo Rizzini (1979), nos afloramentos hematíticos (Canga) ocorre uma fisionomia denominada Campo Ferruginoso. Tal fisionomia foi considerada por Ribeiro \& Walter (1998) como Cerrado Rupestre. Não há consenso entre pesquisadores a respeito de uma terminologia que delimite e individualize essa vegetação enquanto fitofisionomia. Na Serra do Condado, a Vegetação Arbustivo-Lenhosa sobre Canga, foi considerada como uma formação não florestal uniestradificada. Assim como nos campos rupestres propriamente ditos (quartzito), seu estrato herbáceo possui elevada riqueza florística principalmente de Velloziaceae, Eriocaulaceae, Orchidaceae, Bromeliaceae, Gentianaceae, Melastomataceae e Poaceae, sendo essas, muitas vezes, as melhores indicadoras dessas fitofisionomias bem como de seu grau de conservação (Giulietti et al. 2000, Stannard 1995). Assim sendo, justifica-se a subestimativa amostral das famílias Poaceae e Orchidaceae neste estudo por duas razões principais. A primeira é relativa ao método utilizado em levantamentos florísticos que contempla somente materiais reprodutivos como testemunhos. Assim, muitas orquídeas foram observadas, mas não puderam ser registradas nem como morfoespécies, pois se manifestavam vegetativamente apenas por seus pseudobulbos. No caso das gramíneas a razão da subestimativa é outra. Nas áreas mais altas da Serra, onde se localiza a Vegetação Arbustivo-Lenhosa sobre Canga, o acesso para as coletas e o trabalho de campo foi extremamente prejudicado por questões fundiárias e de propriedade, sendo raros os proprietários que permitiram o acesso dos autores a suas terras para a execução do trabalho. Não obstante, a falta de levantamentos florísticos em formações específicas como esta dificulta análises comparativas dessa flora com outras semelhantes. Neste contexto, destaca-se apenas o trabalho desenvolvido em Brumadinho (Viana \& Lombardi 2007), no Quadrilátero Ferrífero, MG, onde registraram 358 espécies de plantas vasculares ocorrentes em canga couraçada e canga nodular. Das 94 espécies encontradas na canga couraçada da Serra do Condado, 31 também foram encontradas em Brumadinho, sendo que tal compartilhamento encontrou-se bem distribuído nas duas áreas de canga aqui comparadas.

As estimativas obtidas através do índice de Sørensen revelaram valores inferiores a $10 \%$ de similaridade corroborando com a significativa diversidade beta analisando-se as fitofisionomias estudadas. O maior compartilhamento de espécies entre a Floresta Montana e a Vegetação sobre Canga se deve, em parte, à presença de espécies florestais tolerantes aos solos litólicos ocorrentes principalmente nas regiões ecotonais dessas duas fitofisionomias. Isto foi percebido nesse trabalho pela ocorrência de um grupo de espécies arbóreas que se desenvolvem sobre a rocha mãe aflorada, caso da Asteraceae Eremanthus spp. (candeia) e da Ericaceae Gaylussacia brasiliensis (Spreng.) Mart. Este cenário é amplamente relatado para regiões onde a Floresta Semidecídua Montana se insere nos Complexos Rupestres de altitude (Benites et al. 2003). O mosaico vegetacional estudado reflete o quão diversa e desconhecida é a flora das regiões montanhosas de Minas Gerais e o quanto sua conservação está ameaçada. A corrida minerária que se instalou na região foi responsável por grande parte do efeito de borda e da fragmentação observados neste estudo, bem como à baixa quantidade de hábitats conectados, fazendo-os ora presentes, ora não, em toda a Serra do Condado.

Embora este estudo seja ainda uma aproximação de toda a flora existente na região (devido às limitações temporal e logística), os resultados mostraram uma riqueza florística elevada com espécies raras e indicadoras das muitas fisionomias que formam a paisagem da Cadeia do Espinhaço. Não obstante, os resultados encontrados em estudos florísticos criteriosos como este são a principal ferramenta no conhecimento da flora de uma região e consequentemente são também importantíssimos na descoberta de 
novas espécies e na conservação das poucas áreas ainda capazes de manter e repor a tão ameaçada diversidade vegetal do estado de Minas Gerais.

\section{Agradecimentos}

A J.A.Silveira e A.L. Souza, pelos auxílios prestados nos trabalhos de campo. Obrigado.

\section{Referências}

ALVARENGA, M.I.N. \& PAULA, M.B. 2000. Planejamento conservacionista em microbacias. Inf. Agropecu. 21(207):55-64.

ANDRADE, P.M., GONTIJO, T.A. \& GRANDI, T.S.M. 1986. Composição florística e aspectos estruturais de uma área de Campo Rupestre do Morro do Chapéu, Nova Lima, Minas Gerais. Rev. Bras. Bot. 9(1):13-21.

ANGIOSPERM PHYLOGENY GROUP - APGII. 2003. An update of the Angiosperm Phylogeny Group classification for the orders and families of flowering plants: APG II. J. Linn. Soc. Lond. Bot. 141:399-436.

ARAÚJO, F.S. 1998. Estudos fitogeográficos do carrasco no nordeste do Brasil. Tese de Doutorado, Universidade Estadual de Campinas, Campinas, $97 \mathrm{p}$.

BENITES, V.M., CAIAFA, A.N., MENDONÇA, E.S., SCHAEFER, C.E. \& KER, J.C. 2003. Solos e vegetação nos complexos rupestres de altitude da Mantiqueira e do Espinhaço. Floresta Ambient. 10(1):76-85.

BRANDÃO, M. \& GAVILANES, M.L. 1990. Mais uma contribuição para o conhecimento da Cadeia do Espinhaço em Minas Gerais (Serra da Piedade)-II. Daphne 1(1):26-43.

CENTRO TECNOLÓGICO DE MINAS GERAIS - CETEC. 1983. Diagnóstico ambiental do Estado de Minas Gerais. Minas Gerais, 158 p. (Série de Publicações Técnicas/SPT010)

CONCEIÇÃO, A.A. \& GIULIETTI, A.M. 2002. Composição florística e aspectos estruturais de campo rupestre em dois platôs no Morro do Pai Inácio, Chapada Diamantina, Bahia, Brasil. Hoehnea 29(1):37-48.

DEAN, W. 1996. A ferro e fogo: a história e a devastação da Mata Atlântica brasileira. Companhia das Letras, São Paulo, 484 p.

DRUMMOND, G.M., MARTINS, C.S., MACHADO, A.B.M., SEBAIO, F.A. \& ANTONINI, Y. 2005. Biodiversidade em Minas Gerais: um atlas para sua conservação. 2 ed. Fundação Biodiversitas, Belo Horizonte, 222 p.

FIDALGO, O. \& BONONI, V.L.R. 1984. Técnicas de coleta, preservação e herborização de material botânico. Instituto de Botânica, São Paulo, $62 \mathrm{p}$.

GENTRY, A.H. 1990. Floristic similarities and differences between Southern Central America and upper and Central Amazonia. In Four neotropical rain forests (A.H. Gentry, ed.). Yale University Press, London, p. 141-160.

GIULIETTI, A.M., MENEZES, N.L., PIRANI, J.R., MEGURO, M. \& WANDERLEY, M.G.L. 1987. Flora da Serra do Cipó: caracterização e lista de espécies. Boletim de Botânica da Universidade de São Paulo 9:1-151.

GIULIETTI, A.M., HARLEY, R.M., QUEIROZ, L.P., WANDERLEY, M.G.L. \& PIRANI, J.R. 2000. Caracterização e endemismos nos campos rupestres da Cadeia do Espinhaço. In Tópicos atuais em botânica (T.B. Cavalcanti \& B.M.T.Walter, orgs). 1 ed. SBB; CENARGEN, Brasília, p. 311-318.

GIULIETTI, A.M., RAPINI, A., ANDRADE, M.J.G., QUEIROZ, L.P. \& SILVA, J. M.C. 2008. Plantas raras do Brasil. Conservação Internacional, Belo Horizonte, 495 p.

HOEHNE, F.C. 1948. Plantas aquáticas. Instituto de Botânica, São Paulo, $168 \mathrm{p}$.

KENT, M. \& COKER, P. 1992. Vegetation description and analysis: a practical approach. Belhaven Press, London, 363 p.

LIMA, H.C. \& GUEDES-BRUNI, R.R. 1997. Serra de Macaé de Cima: diversidade florística e conservação em Mata Atlântica. 1 ed. Jardim Botânico do Rio de Janeiro, Rio de Janeiro, 346 p.
LOMBARDI, J.A. \& GONÇALVES, M. 2000. Composição florística de dois remanescentes de Mata Atlântica do sudeste de Minas Gerais, Brasil. Rev. Bras. Bot. 23(3):255-282.

LOPES, W.P., SILVA, A.L. \& MEIRA NETO, J.A. 2002. Estrutura Fitossociológica de um trecho de vegetação arbórea no Parque Estadual do Rio Doce - Minas Gerais, Brasil. Acta Bot. Bras. 16(4):443-456.

MARQUES, M.C.M. 1997. Mapeamento da cobertura vegetal e listagem das espécies ocorrentes na Área de Proteção Ambiental de Cairuçu, Parati, RJ. Instituto de Pesquisas Jardim Botânico do Rio de Janeiro, Rio de Janeiro, p. 1-96. (Série Estudos e Contribuições, n. 13.)

MEGURO, M., PIRANI, J.R., GIULIETTI, A.M. \& MELLO-SILVA, R. 1994. Phytophysiognomy and composition of the vegetation of Serra do Ambrósio, Minas Gerais, Brazil. Rev. Bras. Bot. 17(2):149-166.

MELO, M.M.R.F., BARROS, F., CHIEA, S.A.C., WANDERLEY, M.G.L., JUNG-MENDAÇOLLI, S.L. \& KIRIZAWA, M. 1991. Flora Fanerogâmica da Ilha do Cardoso. Instituto de Botânica, São Paulo, 165 p. (v. 1)

MELO, L.C.N. \& SALINO, A. 2002. Pteridófitas de duas áreas de floresta da Bacia do Rio Doce no Estado de Minas Gerais, Brasil. Lundiana 3(2):129-139.

MOURÃO, A. \& STEHMANN, J.R. 2007. Levantamento da flora do campo rupestre sobre canga Hematítica couraçada remanescente na mina do Brucutu, Barão de Cocais, Minas Gerais, Brasil. Rodriguésia 58(4):775-786.

MURRAY-SMITH, C., BRUMMITT, N.A., OLIVEIRA FILHO, A.T., BACHMAN, S., MOAT, J., LUGHADHA, E.M.N. \& LUCAS, E.J. 2008. Plant diversity hotspots in the Atlantic coastal forests of Brazil. Conservation Biol. 23(1):151-163.

NÉRI, A.V., MEIRA NETO, J.A., SILVA, A.F., MARTINS, S.V. \& BATISTA, M.L. 2007. Análise da estrutura de uma comunidade lenhosa em área de cerrado sensu stricto no município de Senador Modestino Gonçalves, norte de Minas Gerais, Brasil. Rev. Árvore 31(1):123 -134.

OLIVEIRA FILHO, A.T. 1993. Gradient analysis of an area of coastal vegetation in the state of Paraíba, northeastern Brazil. Edinb. J. Bot. 50(2):217-236.

OLIVEIRA FILHO, A.T., ALMEIDA, R.J., MELLO, J.M. \& GAVILANES, M.L. 1994a. Estrutura fitossociológica e variáveis ambientais em um trecho da mata ciliar do córrego dos Vilas Boas, Reserva Biológica do Poço Bonito, Lavras (MG). Rev. Bras. Bot. 17(1):67-85.

OLIVEIRA FILHO, A.T., VILELA, E.A., GAVILANES, M.L. \& CARVALHO, D.A. 1994b. Comparison of the woody flora and soils of six areas of montane semideciduous forest in Southern Minas Gerais, Brazil. Edinb. J. Bot. 51(3):355-389.

OLIVEIRA FILHO, A.T. \& RATTER, J.A. 1995. A study of the origin of central Brazilian forests by the analysis of plants species distribution patterns. Edinb. J. Bot. 52(2):141-194.

OLIVEIRA FILHO, A.T. \& FONTES, M.A.L. 2000. Patterns of floristic differentiation among Atlantic Forest in South-Eastern Brazil and the influence of climate. Biotropica 32(suppl. 5):1-16.

OLIVEIRA FILHO, A.T., CARVALHO, D.A., FONTES, M.A.L., BERG, E.V.D., CURI, N. \& CARVALHO, W.A.C. 2004. Variações estruturais do compartimento arbóreo de uma floresta semidecídua alto-montana na chapada das Perdizes, Carrancas, MG. Rev. Bras. Bot. 27(2):291-309.

OLIVEIRA FILHO, A.T., TAMEIRÃO NETO, E., CARVALHO, W.A.C., BRINA, A. E., WERNECK, M., VIDAL, C. \& REZENDE, S. 2005. Análise florística do compartimento arbóreo de áreas de Floresta Atlântica sensu lato na região das Bacias do Leste (Bahia, Minas Gerais, Espírito Santo e Rio de Janeiro). Rodriguésia 56(87):185-235.

PEREIRA, I.M., OLIVEIRA FILHO, A.T., BOTELHO, S.A., CARVALHO, W.A.C., FONTES, M.A.L., SCHIAVINI, I. \& SILVA, A.F. 2006. Composição florística do compartimento arbóreo de cinco remanescentes florestais do maciço do Itatiaia, Minas Gerais e Rio de Janeiro. Rodriguésia 57(1):103-126.

PEREIRA, J.A.A. 2003. Efeitos dos impactos ambientais e da heterogeneidade ambiental sobre a diversidade e estrutura da comunidade arbórea de 20 fragmentos de florestas semidecíduas da região do Alto Rio Grande, 
Minas Gerais. Tese de Doutorado, Universidade Federal de Minas Gerais, Belo Horizonte, $156 \mathrm{p}$

PEREIRA, J.A.A., OLIVEIRA FILHO, A.T. \& LEMOS FILHO, J.P. 2007. Environmental heterogeneity and disturbance by humans control much of the tree species diversity of fragments of tropical montane seasonal forests in SE Brazil. Biodiversity Conserv. 16(6):1761-1784.

PIFANO, D.S., VALENTE, A.S.M., CASTRO, R.M., PIVARI, M.O.D., SALIMENA, F.R.G. \& OLIVEIRA FILHO, A.T. 2007. Similaridade entre as fisionomias da vegetação do Morro do Imperador, Juiz de Fora, MG, com base na composição de sua flora fanerogâmica. Rodriguésia 58(8):885-904.

POTT, A. \& POTT, V.J. 2000. Plantas aquáticas do Pantanal. Editora da UnB, Brasília, $404 \mathrm{p}$.

RAUNKIAER, C. 1934. The life forms of plants and statistical geography. Clarendon, Oxford.

RIBEIRO, J.F. \& WALTER, B.M.T. 1998. Fitofisionomia do bioma Cerrado. In Cerrado: ambiente e flora (S.M. Sano \& S.P. Almeida). EMBRAPA, Planaltina, p. 89-152.

RIZZINI C.T. 1979. Tratado de Fitogeografia do Brasil. HUCITEC; EDUSP, São Paulo.

RODRIGUES, R.R. \& NAVE, A.G. 2000 Heterogeneidade florística das matas ciliares. In Matas ciliares: conservação e recuperação (R.R. Rodrigues \& H.F. Leitão Filho). Universidade de São Paulo; Fapesp, São Paulo, p. $45-71$

SALIS, S.M., SHEPHERD, G.J. \& JOLY, C.A. 1995. Floristic comparison of mesophytic semideciduous forest of the interior of the state of São Paulo, Southeast Brazil. Vegetation 119(2):155-164.

SCOLFORO, J.R.S. \& CARVALHO, L.M.T. 2006. Mapeamento e inventário da flora nativa e dos reflorestamentos de Minas Gerais. Editora UFLA, Lavras.

SCUDELLER, V.V., MARTINS, F.R. \& SHEPHERD, G.J. 2001. Distribution and abundance of arboreal species in the Atlantic Ombrophilous Dense Forest in Southeastern Brazil. Plant Ecol. 152(2):185-199.

SCUDELLER, V.V. 2002. Análise fitogeográfica da Mata Atlântica - Brasil. Tese de Doutorado, Universidade Estadual de Campinas, Campinas, 204 p.
SILVA, A.F. \& SHEPHERD, G.J. 1986. Comparações florísticas entre algumas matas brasileiras utilizando análise de agrupamento. Rev. Bras. Bot. 9(1):81-86.

SMITH, A.R., PRYER, K.M., SCHUETTPELZ, E., KORALL, P., SCHNEIDER, H. \& WOLF, P.G. 2006. A classification for extant ferns. Taxon 55(3):705-731.

SOUZA, V.C. \& LORENZI, H. 2008. Botânica sistemática: guia ilustrado para identificação das famílias de Angiospermas da flora brasileira em APG II. 2 ed. Instituto Plantarum, Nova Odessa, 640 p.

STANNARD, B.L. 1995. Flora of the Pico das Almas, Chapada Diamantina, Bahia, Brazil. Royal Botanic Gardens, Kew, 853 p.

TORRES, R.B., MARTINS, F.R. \& KINOSHITA, L.S. 1997. Climate, soil and tree flora relationships in forests in the state of São Paulo, Southeastern Brasil. Rev. Bras. Bot. 20(1):41-49.

TRYON, R.M. \& TRYON, A.F. 1982. Ferns and allied plants, with special reference to Tropical America. Springer-Verlag, New York, 857 p.

VELOSO, H.P., RANGEL, A.L.R. \& LIMA, J.C.A. 1991. Classificação da vegetação brasileira, adaptada a um sistema universal. IBGE, Rio de Janeiro, $124 \mathrm{p}$.

VIANA, P.L. \& LOMBARDI, J.A. 2007. Florística e caracterização dos campos rupestres sobre canga na Serra da Calçada, Minas Gerais, Brasil Rodriguésia 58(1): 159-177.

VINCENT, R.C. \& MEGURO M. 2008. Influence of soil properties on the abundance of plant species in ferruginous rocky soils vegetation, southeastern Brazil. Rev. Bras. Bot. 31(3):377-388.

WERNECK, M.S., PEDRALLI, G., KOENIG, R. \& GISEKE, L.F. 2000. Florística e estrutura de três trechos de uma floresta semidecídua na Estação Ecológica do Tripuí, Ouro Preto, MG. Rev. Bras. Bot. 23(1):97-106.

Recebido em 12/05/09

Versão reformulada recebida em 22/01/10

Publicado em $27 / 01 / 10$ 